DOI: 10.19085/journal.sijmas030101

\title{
Big data processing using Open Source Software- A Questionnaire on the data science
}

\author{
Andrew McCullum \\ University of Graz, Graz, Austria.
}

oScholedge International Journal of Multidisciplinary \& Allied Studies (ISSN 2394-336X), Vol.03, Issue 01 (2016) pg1-8. Published by: Scholedge R\&D Center [www.theSCHOLEDGE.org] [Email: sijmas@scholedge.org]

\begin{abstract}
The proceeding with development of monstrous and different information volumes, and the development of information concentrated applications, has exhibited a need to discover compelling method for information administration over all areas. By late report, organizations confront an enormous expertise crevice in the administration of huge information, with the whole developing from 400 in 2007 to 4,000 in 2012 in the United Kingdom alone. Notwithstanding this, there is a general absence of comprehension among understudies of current information investigation forms, which are turning out to be critical for future difficulties with the development of the Internet of Things (IoT) and ongoing information.
\end{abstract}

Keywords: Big data, open source software, data science, programming, IT software

\section{Discussion}

As a PC researcher, contemplating and fabricating demonstrating and reenactment applications, I was at first puzzled as to the fascination towards the term huge information. Business appears to concentrate on Hadoop-related programming for information investigation, and having Hadoop-related activities on your resume can be a reward. As an instructor of distributed computing and programming designing, I chose to relegate two understudies Hadoop-related undertakings for huge information administration with a "savvy urban communities" center, and talked with them about their learning targets to see what they considered the advancements.

As an essential, the understudies were given full opportunity to look at the theme of Hadoop enormous information preparing, and requested that investigate whichever devices they needed to around there. Hadoop is an arrangement of hardware that backings the running of enormous information applications with different occupation executions to permit monstrous measures of information to be prepared rapidly. It is a domain to run MapReduce employments that are normally sorted in clump. Hadoop has ended up a standout amongst the most critical apparatuses in science ventures which require examining information. A portion of the Hadoop-related instruments my understudies researched included:

- Apache Ambari: A structure for overseeing and observing Hadoop bunches 
- Apache Pig: A stage for running code for breaking down expansive information set of information.

- Apache Sqoop: A device utilized for moving information in the middle of Hadoop and other information stores

- Apache ZooKeeper: A device utilized for giving synchronization and keeping up the set up of data.

- Apache Spark: A more up to date instrument used to run examination quicker on a few sorts of information.

- Apache Flume: A framework that accumulates data that is later put away in HDFS.

- Apache Hive: An instrument which permits clients to utilize a SQL-like dialect to break down information.

- Apache Oozie: An instrument to begin examination employments that have been softened into various parts up the right succession.

- Hadoop Distributed File System (HDFS): A structure for separating information between hubs.

- HCatalog: An instrument which is utilized to transfer tables and is utilized to oversee information, which empowers clients to break down information utilizing distinctive preparing apparatuses like Pig, Hive, and MapReduce.

After the understudies effectively completed their last year expositions, I posed a few inquiries to comprehend what they gained from the experience. Here are the reactions from 
both of my understudies, Saudamini Sonalker and Rafiat Olubodun Kadiri, who were doing autonomous tests with Hadoop.

Why would you have liked to learn Hadoop? Just to gain some new useful knowledge, or would you say you were impacted by industry enthusiasm for the task?

Saudamini: I was basically roused to chip away at this point subsequent to having perused a book about enormous information by Victor Mayer-Schonberger and Kenneth Cukier: Big Data: A Revolution That Will Transform How We Live, Work, and Think. The prescient way of apparatuses that help huge information preparing is the thing that attracted me to adapting more about it. Focusing on shrewd city information was additionally a fascinating component of this undertaking. I need to learn and see more about how city information can be used to make urban areas proficient, green, and keen.

Rafiat: I picked the theme of Hadoop in light of the fact that it is another territory; it is a trendy expression, and as of late has been overwhelming the business sector. Diverse organizations make utilization of it, including online networking sites, for example, Twitter and Facebook utilizing Hadoop to mine information for various purposes, empowering them to settle on sensible business choices.

What do organizations utilize enormous information for? What sort of inquiries would they say they are utilizing it to inquire?

Saudamini: Companies utilize enormous information for various purposes. Amazon uses it for proposals, Skyscanner and Kayak at monitoring so as to change flight costs a person's past inquiries, and Google utilizes it to decide the request of query items. An intriguing utilization of huge information was Amsterdam's Energy Atlas venture. It utilized vitality utilization information from inside of the city to advance renewable vitality by making its nationals mindful of their own use.

Rafiat: Different organizations have diverse utilization of enormous information. The use of huge information for an organization relies on upon what sort of administration they give to the general population. Organizations like eBay and Amazon utilize huge information to make forecasts of what clients might crave as indicated by their past buy history and comparable buy by different clients

What issues did you have when introducing Hadoop while setting up the sandbox environment? What drove you to pick Hortonworks Sandbox for your trials?

Saudamini: I investigated two or three choices before settling on Hortonworks Data Platform. The real purpose behind picking it was on the grounds that it is open source and free. Different contenders like MapR, Amazon Web Services and Cloudera, however great the stages, were costly. Be that as it may, there were strict memory necessities to set up the sandbox. A 64-bit processor was important to get to the sandbox by means of virtual machine, and it required no less than 4GB RAM. This backed the procedure off for me and the stage has no adaptability as far as prerequisites. 
Rafiat: There are a significant number of open Hadoop groups that have been intended for putting away and dissecting a lot of unstructured information in a figuring domain. They are accessible on cloud bases, for example, Heroku, Hortonworks Sandbox, Azure, and others.

After a couple seeks, I chose to utilize Hortonworks Data Platform, an open source apache Hadoop information stage. The framework necessities included utilizing Windows or Mac working framework, no less than $4 G B$ of RAM, a virtual machine environment, and a 64-bit chip that backings virtualization.

The initial step was to download a virtual machine, then download the sandbox from the Hortonworks site. After this I associated with the sandbox with the given IP address.

There were some negative perspectives to utilizing the Hortonworks sandbox for examination, which regardless I confront. I was not able access the sandbox with the given IP address for some time, however after numerous trials, it worked. Second, the virtual machine backed off my PC the minute it is exchanged on, and it set aside quite a while for a question to stack.

Further, I confront issues like when my machine goes off itself without permitting me to close down the virtual machine down myself, whenever I switch it on, the virtual machine concocts arrangement blunders which confines me from getting to the sandbox. Another issue that I face is not having the capacity to get to a percentage of the apparatuses now and then, which backs off my exploration.

How does the Hortonworks Data Platform work?

Saudamini: The stage can be partitioned into three layers: the information access layer, group asset administration, and HDFS. The information access layer is the place the client transfers, inventories, and oversees information; one uses this layer to enter their Hive/Pig occupations for the framework to perform. Bunch asset administration (YARN) is an engineering center point for information preparing motors so various applications can be keep running on the HDFS. This layer basically fills in as an interpreter for the other two. At long last, HDFS is the place the MapReduce employments are keep running in parallel between the expert and slave hubs.

Ambari is an online GUI that can identify with the basic hardware and permits client to set up and deal with a Hadoop bunch.

Rafiat: When getting to the sandbox, I was coordinated to a page where I had entry to various apparatuses like Hive, File program, Pig, Job program, and others. I could transfer diverse sort of documents (compress record, csv, xml), then make tables from apparatuses such as Hive, Pig and HCatalog with the record that has been transferred through the document program symbol. I could then make questions to give diverse kind of tables with various criteria to fit a necessity.

Ambari can be utilized to screen and oversee Hadoop groups. Checking the result of the questions that have been completed, and demonstrating the impact of the inquiries on the CPU utilization, memory use, system use, and so forth. 
What apparatuses did you investigate, and what were the new things you learned all the while?

Saudamini: Initially, I anticipated investigating Pig and Hive, however I had issues running the Pig script on Hortonworks Sandbox and henceforth stayed with Hive. Hive Query Language is fundamentally the same to SQL, along these lines on the off chance that somebody is capable in the last mentioned, then they shouldn't have an issue working with the apparatus. On Hortonworks Sandbox, Hive has a graphical client interface called Beeswax. Hive changes over inquiries you compose into MapReduce occupations. Regardless of whether one needs numerous alternatives to process information relies on upon the expertise sets of the clients chipping away at a vast venture. Hive reduces the need to prepare or contract outside assets with a specific end goal to fill in the crevice. The adaptability is valuable in situations such as those.

Rafiat: I utilized Hive, which utilizes a SQL-like scripting dialect which is known as HiveQL. It is suitable for clients that are acquainted with organized question dialect. Moreover, Pig was utilized as a dialect for information examination and it is likewise an abnormal state preparing layer on Hadoop. It comprise of a dialect called Pig Latin.

What sort of records did you handle? Brilliant city datasets?

Saudamini: I focused on savvy city information, particularly London activity and social information.

Rafiat: Smart city information were utilized for this examinations the greater part of the information was recovered from ITU information measurements site and London information store site.

What were the objectives of the examinations? What did you accomplish?

Saudamini: The objective was to watch execution of the basic apparatus and group loads. Subsequent to preparing distinctive huge information documents I analyzed aftereffects of $\mathrm{CPU}$ execution, group loads, memory use, and system utilization.

Transport and social information was handled on the stage to check the practicality of actualizing keen workplaces inside of London to lessen activity and spare individuals' chance. The theory was that there would be a relationship between's high activity districts and wards with most work destinations. In spite of the fact that that held up much of the time, these districts were not in focal London such as at first envisioned.

Rafiat: The objective of the investigation was to break down arrangement of information that will be recovered from various sources such as ITU (International Telecommunication Union) site, London information store, open information sets on Amazon Web Services, and so on. The point was to utilize volume as one the criteria to consider while examining the information. By doing this, the test will have the capacity to show to what extent it will take for the information to be prepared.

In the event that you were given a task now for enormous information handling, how might you approach it? 
Saudamini: If time is not a worry and cost is an issue then I would suggest utilizing Hortonworks Sandbox as its adaptability towards sort of information source, information preparing device alternatives and Ambari environment give a wholesome information administration experience. Be that as it may, if time is of the embodiment and cash not an element then it is useful to take a gander at different alternatives which give a comparable client involvement in the cloud.

Rafiat: I would utilization of Hortonworks Data Platform on a different machine committed to the stage, as my own particular machine was not high spec.

As a software engineering understudy, do you think for information administration we ought to dependably utilize apparatuses like these?

Saudamini: If the dataset you are working with it substantial, then I think it is prudent to utilize enormous information instruments like these. Their adaptability and speedy handling make them perfect to be conveyed as answers for shrewd city issues. In any case, I am not persuaded that we ought to dependably utilize them. We could really attempt and abstain from utilizing these devices if the dataset doesn't request it. A considerable measure of the investigative capacities should be possible by other $\mathrm{Bl}$ apparatuses. Enormous information apparatuses can have a precarious expectation to absorb information, and preparing clients ought to be figured in while sending frameworks that use them.

Rafiat: Data administration is a critical point There are diverse preferences to overseeing information successfully as an understudy, individual or association. This incorporates averting information duplication, which will permit memory space to be spared. It permits approval of results if need be. Information administration permits appropriate comprehension of information, the utilization of inquiries to give particular data required, so information can be seen effortlessly.

Taking everything into account, we got blended results on the utilization of instruments to process ig information applications. An open Hadoop information stage appeared like the conspicuous decision at the time. As already portrayed, MapReduce is at the center of a Hadoop Distributed File System. Hortonworks Sandbox is outfitted with YARN, the second era of MapReduce. It isolates the two essential assignments and makes the procedure more effective. YARN underpins group and also constant preparing ventures. The Hortonworks Data Platform has the capacity to adjust to the client's current information design which is a colossal in addition to. Notwithstanding the stage being without cost, productive and versatile, it likewise has a broad rundown of instructional exercises and client construct guides in light of utilizing the administrations it gives.

There are a considerable measure of huge information handling stages accessible as an aftereffect of it being the present popular expression. Most administrations; Amazon Web Services, Cloudera, MapR and so forth to give some examples, charge the client relying on the activity and measure of information they prepare. Cloudera's site asserts, "The organization's venture information center $(\mathrm{EDH})$ programming stage engages associations to store, prepare and break down all undertaking information, of whatever sort, in any volume-making astounding cost-efficiencies and in addition empowering business change." 
The present move towards open information producing gigantic measures of information, needs constant preparing requiring smart answers for procedure it. Having more apparatuses which are open source can fuel further open information research affecting registering, as well as sociologies, where financial specialists and governments can make utilization of huge information as well.

\section{References}

Abràmoff, M. D., Magalhães, P. J., \& Ram, S. J. (2004). Image processing with ImageJ. Biophotonics international, 11(7), 36-42.

Agrawal, D., Das, S., \& El Abbadi, A. (2011, March). Big data and cloud computing: current state and future opportunities. In Proceedings of the 14th International Conference on Extending Database Technology (pp. 530-533). ACM.

Bird, S. (2006, July). NLTK: the natural language toolkit. In Proceedings of the COLING/ACL on Interactive presentation sessions (pp. 69-72). Association for Computational Linguistics.

Chatti, M. A., Dyckhoff, A. L., Schroeder, U., \& Thüs, H. (2012). A reference model for learning analytics. International Journal of Technology Enhanced Learning, 4(5-6), 318-331.

Childs, H. (2013). Vislt: An end-user tool for visualizing and analyzing very large data.

Cole, J., \& Foster, H. (2007). Using Moodle: Teaching with the popular open source course management system. " O'Reilly Media, Inc.".

Dai, L., Gao, X., Guo, Y., Xiao, J., \& Zhang, Z. (2012). Bioinformatics clouds for big data manipulation. Biology direct, 7(1), 1-7.

Demirkan, H., \& Delen, D. (2013). Leveraging the capabilities of service-oriented decision support systems: Putting analytics and big data in cloud.Decision Support Systems, 55(1), 412421.

Ducheneaut, N. (2005). Socialization in an open source software community: A sociotechnical analysis. Computer Supported Cooperative Work (CSCW),14(4), 323-368.

Ferguson, R. (2012). Learning analytics: drivers, developments and challenges. International Journal of Technology Enhanced Learning, 4(5-6), 304-317.

Foster, I. (2005). Service-oriented science. Science, 308(5723), 814-817.

Fox, A., Griffith, R., Joseph, A., Katz, R., Konwinski, A., Lee, G., ... \& Stoica, I. (2009). Above the clouds: A Berkeley view of cloud computing.Dept. Electrical Eng. and Comput. Sciences, University of California, Berkeley, Rep. UCB/EECS, 28(13), 2009.

Raghupathi, W., \& Raghupathi, V. (2014). Big data analytics in healthcare: promise and potential. Health Information Science and Systems, 2(1), 3. 
Schneider, C. A., Rasband, W. S., \& Eliceiri, K. W. (2012). NIH Image to ImageJ: 25 years of image analysis. Nat methods, 9(7), 671-675.

Sonnenburg, S., Braun, M. L., Ong, C. S., Bengio, S., Bottou, L., Holmes, G., ... \& Rätsch, G. (2007). The need for open source software in machine learning. 